\title{
Una regla de predicción clínica permite descartar fracturas de tobillo y pie
}

\author{
Objetivo \\ Evaluar la precisión de la Regla de Ottawa (ver cuadro 1) para \\ excluir fracturas de tobillo y zona media del pie.
}

\section{Fuentes de datos}

Medline, Cochrane, Embase, CINAHL, Science Citation Index Database y contacto con autores.

\section{Selección de estudios}

La revisión incluyó 27 estudios de buena calidad (15.581 pacientes con antecedente de traumatismo dentro de las $48 \mathrm{hs}$. previas) que utilizaban la regla de Ottawa para descartar fractura de tobillo o pie. Se incluyeron trabajos publicados desde 1990 hasta 2002 y de los cuales se pudiera calcular las tasas de falsos positivos ${ }^{*}$ y negativos* $^{*}$ y razones de probabilidad negativa* (LR-). Participaron 2 revisores independientes.

\section{Extracción de datos}

Se obtuvieron datos sobre cantidad de pacientes, características demográficas, lugar y tipo de regla de Ottawa empleada, calidad y puntos finales de los estudios. Estos últimos incluyeron sensibili-

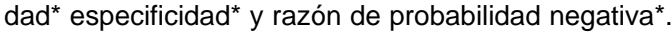

\section{Cuadro 1. Regla de Ottawa para fractura de tobillo y pie}

\section{1- Imposibilidad de dar 4 pasos}

2- Dolor localizado en los maléolos

3- Dolor localizado en la zona del escafoides

4- Dolor localizado en la base del quinto metatarsiano

Si algún punto es positivo es necesaria mayor evaluación para descartar fractura

\section{Resultados principales}

De los 15.581 pacientes incluidos, sólo 47 (0,3\%) presentó un resultado falso negativo con la aplicación de la regla. En la tabla se resumen las principales características operativas de esta regla de predicción clínica.

Tabla 1. Características operativas de una regla de Ottawa negativa (un resultado negativo en los 4 puntos)

\begin{tabular}{l|c|c}
$\begin{array}{c}\text { Tipo de fractura } \\
\text { (n de estudios) }\end{array}$ & $\begin{array}{c}\text { LR - } \\
\text { (IC 95\%) }\end{array}$ & $\begin{array}{c}\text { Probabilidad de fractura } \\
\text { (\%)**(IC 95\%) }\end{array}$ \\
\hline Todas (27) & $0,10(0,06-0,16)$ & $1,73(1,05-2,75)$ \\
\hline Tobillo (12) & $0,08(0,03-0,18)$ & $1,39(0,53-3,08)$ \\
\hline Pie (8) & $0,08(0,03-0,20)$ & $1,39(0,53-3,41)$ \\
\hline Combinado (10) & $0,17(0,10-0,30)$ & $2,91(1,73-5,03)$ \\
\hline
\end{tabular}

* *Calculada con una prevalencia de fractura de $15 \%$

\section{Conclusiones}

La regla de Ottawa es muy sensible para descartar fractura de tobillo y pie en pacientes que se presentan a la guardia con un traumatismo agudo de tobillo.

Fuente de financiamiento: sin conflictos de interés

\section{Comentario}

Las lesiones traumáticas de tobillo y pie son un motivo frecuente de consulta en los servicios de emergencias y también en el consultorio. Del total de pacientes que consultan por este motivo, menos del $15 \%$ tienen fracturas.

Las reglas de Ottawa son instrumentos de predicción clínica desarrollados por el grupo de trabajo de elaboración de Guías de Práctica Clínica de Canadá en 1992 y validadas a nivel internacional. Tienen como objetivo seleccionar a aquellos pacientes con bajo riesgo de presentar una fractura; y consisten en una serie de preguntas para evaluar el trauma de tobillo y zona media del pie (ver cuadro 1).

Esta regla es muy simple, se basa solamente en el dolor local y la habilidad para caminar, haciéndola muy práctica para el médico de emergencias, apremiado por el tiempo y la gran cantidad de pacientes. Además, la alta sensibilidad para descartar fracturas (casi $100 \%$ ) que posee esta regla no varió demasiado de acuerdo a la edad de los pacientes ni la prevalencia de fractura'.

La aplicación de esta regla permitiría evitar la radiografía en pacientes que sólo presentan una lesión leve de tobillo y pie, reduciendo el número de placas innecesarias en $30-40 \%$ y los tiempos de espera de los pacientes en la guardia ${ }^{2}$. Aunque es necesario un estudio de costo-efectividad, se puede inferir que la aplicación de la regla de Ottawa sería costo-efectiva y reduciría también los costos de atención.
Ante un instrumento tan sencible como esta regla (menos de $1 \%$ de fracturas no detectadas) uno se encuentra, sin embargo, con una mayor o menor resistencia a su aplicación en el "mundo real", como casi todas las reglas de predicción clínica. Esto puede deberse a un sentimiento de "pérdida de autonomía" por parte del médico, que recibe el diagnóstico "enlatado", pero además a la preocupación de pasar por alto un diagnóstico importante como una fractura, con sus implicancias clínicas y también medico-legales. Esto nos lleva a la siguiente pregunta: ¿Cuál sería la tasa de falsos negativos por debajo de la cual el médico podría aplicar tranquilo una regla de predicción? La respuesta no es clara y como expresa Fletcher ${ }^{1}$ en su comentario del artículo, es un punto a ser discutido en la comunidad y en el ámbito legal y no solamente dentro del círculo médico.

\section{Conclusiones de las comentadoras:}

La regla de Ottawa es muy precisa para descartar fractura de tobillo y pie luego de un traumatismo, y se convierte en un elemento importante que ayuda al diagnóstico de las lesiones graves del tobillo y pie, permitiendo disminuir las placas innecesarias. Sería un instrumento interesante para aplicar en la guardia aunque sin olvidar la evaluación personal de cada paciente y su contexto, elementos imprescindibles en el momento de tomar una decisión clínica.

\section{Dra. Marcela López y Dra.Victoria Wurcel. [ Unidad de Medicina Familiar y Preventiva. Hospital Italiano de Buenos Aires. ]}

